\title{
Avaliação das Condições Logísticas para a Adoção do ECR nos Supermercados Brasileiros
}

\author{
Cláudio Felisoni de Ângelo \\ João Paulo Lara de Siqueira
}

\begin{abstract}
RESUMO
O presente artigo tem dois objetivos distintos. O primeiro é o de identificar os requisitos necessários à implantação da filosofia do efficient consumer response (ECR) por parte dos supermercados. O segundo propósito é o de avaliar as condições logísticas atuais das principais redes brasileiras em termos da utilização das práticas propostas pelo $E C R$. A identificação dos requisitos para a introdução de tais procedimentos é feita com base na literatura e em entrevistas com especialistas. A situação atual dos supermercados brasileiros é avaliada com base em uma pesquisa de campo. Conclui-se que o relacionamento dos supermercados com a indústria ainda é muito pouco expressivo. A principal razão apontada é a baixa utilização do eletronic data interchange (EDI).
\end{abstract}

Palavras-chaves: supermercados; logística; ECR; EDI.

\begin{abstract}
This paper has two different purposes. The first one is to establish the main requirements necessary to settle the efficient consumer response (ECR) ideas. Secondly, it is also intended to unveil the present logistic conditions of Brazilian supermarket industry related to the previous identified requirements to the ECR approach. The requirements are pointed out considering interviews with experts and literature revision. The present situation of Brazilian supermarkets is discussed based on a research carried out with 21 companies from the group of the most important Brazilian chains. The main conclusion is that the integration of Brazilian supermarkets with their suppliers is still very weak. The limited use of electronic data interchange (EDI) is the most important explanation for this finding.
\end{abstract}

Key words: supermarkets; logistics; ECR; EDI. 


\section{INTRODUÇĀO}

O processo de globalização atualmente em curso tem implicações não só econômicas, mas também sociais, tecnológicas, culturais e políticas. Nesse contexto, o sistema produtor de bens, de forma geral, enfrenta novos desafios, na produção e também na distribuição.

É decorrência destes condicionantes a importância crescente que vêm assumindo os meios de organização dos sistemas de produção e distribuição: a logística. Segundo o Council of Logistic Management dos Estados Unidos, citado por Bowersox e Closs (1996, p. 4), define-se logística como "o processo de planejamento, implementação e controle, de forma eficiente e eficaz, do fluxo e armazenamento de bens, serviços e informação a eles relacionados, desde o ponto de origem até o ponto de consumo, com vistas a se adequar às necessidades do cliente".

Essas idéias, que não são novas, vêm sendo recentemente discutidas, no âmbito da indústria de supermercados, sob a denominação Efficient Consumer Response (ECR). O ECR corresponde exatamente ao conceito de gerenciamento dos canais de suprimentos.

Em 1996 surgiu o Movimento ECR Brasil, posteriormente transformado na Associação ECR Brasil, apoiado por várias indústrias, empresas e entidades do setor supermercadista.

Supõe-se que a introdução dos princípios propostos na estratégia ECR contribua para ampliar efetivamente a produtividade das relações fabris e comerciais. Segundo Dib (apud Cooper e Lybrand, 1996, p. 16), "nos Estados Unidos, a estimativa inicial de redução de custos em toda a cadeia de distribuição era de US\$ 30 bilhões (Joint Industry Project on ECR, 1993). Na Europa, por sua vez, é esperada uma redução de custo de US\$ 33 bilhões".

Os supermercados ganharam expressão internacional, a partir de meados da década de 50. No Brasil, a fraqueza ou ausência de outros formatos varejistas é traduzida em uma relevância ainda maior do segmento supermercadista. Segundo os dados divulgados pela AC Nielsen (1999), o setor supermercadista brasileiro possui, atualmente, um total 58.296 lojas de auto-serviço, distribuídas por 3.998 cadeias $^{(1)}$ 
De acordo com Araújo (1999), em 1998 o setor de supermercados, no Brasil, faturou R \$ 55,5 bilhões e empregava 666.752 pessoas. Ainda segundo Araújo (1999), pode-se inferir que os supermercados no Brasil movimentam aproximadamente o equivalente a $6,1 \%$ do Produto Interno Bruto.

As fusões que o setor tem experimentado recentemente não têm inibido a competição, muito pelo contrário. A fase de relativa estabilidade na economia nacional, além de estimular a vinda de empresas comerciais estrangeiras, acabou facilitando a comparação de preços por parte do consumidor, acirrando ainda mais a concorrência.

Nesse ambiente, em que a competição obriga a realização da atividade com margens reduzidas, é fundamental que as empresas comerciais atentem para as condições operacionais.

Este artigo tem dois objetivos. O primeiro é o de determinar quais são os requisitos na área de logística para a adoção do ECR nos supermercados. Esses requisitos devem constituir uma série de técnicas, práticas e ferramentas, incluindo-se equipamentos, que as empresas devem dominar e possuir para poderem colocar-se em condições de adotar tal estratégia. $O$ segundo objetivo é de verificar se os supermercados brasileiros reúnem os requisitos logísticos para a adoção do ECR.

O artigo está organizado em cinco seções. Na primeira seção são discutidos os impactos da evolução da tecnologia nos processos de comunicação. No tópico subseqüente são apresentados o conceito de gerenciamento da cadeia de suprimentos e os princípios do ECR. No item três são estabelecidas as exigências para a introdução do ECR. A quarta seção apresenta os resultados de uma pesquisa de campo que investigou a situação dos supermercados brasileiros relativamente aos requisitos impostos pela filosofia do ECR. Por último, são apresentadas as conclusões gerais do estudo.

\section{A Tecnologia para a Globalização}

Para Mcluhan e Fiore (apud Waters, 1996, p. 35-36) "os circuitos eletrônicos subverteram o regime de tempo e espaço e despejam sobre nós, instantaneamente e continuamente, as preocupações de todos os homens. Eles reconstituíram o diálogo em uma escala global". Ianni (1995, p. 94) concorda com McLuhan e Fiore (apud Waters, 1996), quando diz que "os meios de comunicação de massa, 
potenciados por essas tecnologias, rompem ou ultrapassam fronteiras, culturas, idiomas, religiões, regimes políticos, diversidades e desigualdades socioeconômicas e hierarquias raciais, de sexo e idade". O Quadro 1 explicita e demonstra a velocidade de evolução da tecnologia de informação.

Outro elemento importante neste processo de avanço foi a queda do custo das tecnologias de comunicação. Apenas para dar um exemplo, segundo dados do Banco Mundial uma ligação telefônica de três minutos entre Londres e Nova York baixou de aproximadamente U\$ 250, na década de 30, para menos de U\$ 10 em 1996 (em U\$ de 1990) (Gazeta Mercantil, 1996).

\section{Quadro 1: Evolução da Tecnologia de Comunicação e de Informática}

\begin{tabular}{|c|c|}
\hline 1436 & Gutemberg inventa a imprensa \\
\hline 1844 & Morse inventa o telégrafo (com fio) \\
\hline 1876 & Graham Bell inventa o telefone \\
\hline 1894 & Marconi inventa o rádio \\
\hline 1947 & $\begin{array}{l}\text { É construído nos Estados Unidos o ENIAC, o primeiro computador } \\
\text { eletrônico }\end{array}$ \\
\hline 1955 & É inventada a fibra ótica \\
\hline 1957 & $\begin{array}{l}\text { O primeiro satélite artificial, o Sputinik, é colocado em órbita pelo Governo } \\
\text { da URSS }\end{array}$ \\
\hline 1966 & É inventado o aparelho de fac simile (fax) \\
\hline 1969 & $\begin{array}{l}\text { É criada a Arpanet, rede entre os computadores da University of } \\
\text { California, Los Angeles e do Stanford Research Institute, origem da } \\
\text { Internet }\end{array}$ \\
\hline 1974 & $\begin{array}{l}\text { É criado o transmission control program (TCP), programa para a troca } \\
\text { de arquivos entre computadores }\end{array}$ \\
\hline 1975 & É criado o personal computer (PC), que deu origem aos atuais micros \\
\hline 1976 & $\begin{array}{l}\text { É criado o modem (modulator / demodulator), que permite a transmissão } \\
\text { de dados pela linha telefônica }\end{array}$ \\
\hline 1985 & É lançada a $1^{\text {a }}$ versão do Windows \\
\hline 1989 & É criada a world wide web (WWW), a área gráfica da Internet \\
\hline 1991 & Primeira conexão do Brasil com a Internet, feita pela Fapesp \\
\hline 1994 & É lançado o Netscape \\
\hline 1995 & A Internet é aberta ao público brasileiro pela Embratel \\
\hline 1997 & $\begin{array}{l}\text { A Receita Federal coloca à disposição dos contribuintes brasileiros a } \\
\text { declaração de rendas pela Internet }\end{array}$ \\
\hline
\end{tabular}

Fonte: adaptado das revistas Wired (1999) e Info Exame (1999). 
A logística foi impactada de forma intensa por essas novas tecnologias. A possibilidade de conexão entre os computadores das empresas permite que a troca de informações ocorra de forma quase instantânea. Essas mudanças conferem às empresas de hoje um poder de planejamento, operação e controle de seus processos que, há poucas décadas, era impraticável.

\section{A Cadeia de Abastecimento e o ECR}

Um conceito central na filosofia do ECR é o de cadeia de abastecimento. Segundo Porter (1989, p. 33) "toda empresa é uma reunião de atividades que são executadas para projetar, produzir, comercializar, entregar e sustentar seu produto". O autor aplica o mesmo conceito de cadeia de valor no relacionamento entre organizações: "os elos existem não só dentro da cadeia de valores de uma empresa, mas também entre a cadeia de uma empresa e as cadeias de valores dos fornecedores e dos canais" (Porter, 1989, p. 46).

A cadeia de valor proposta por Porter (1989), quando vista sob uma ótica ampla, englobando desde os produtores até os consumidores finais, ajusta-se à idéia de cadeia de abastecimento (ou supply chain) utilizada pelos autores da área de logística. Ballou (1995, p. 348), por exemplo, afirma que "as atividades logísticas, como quaisquer outras, exigem elevado grau de gestão inter e intrafirmas".

O conceito de gerenciamento da cadeia de abastecimento é expresso também por Bowersox e Closs (1996, p. 33) da seguinte maneira: "para serem totalmente eficazes no ambiente competitivo de hoje, as empresas devem expandir seu comportamento integrado, de modo a incorporar clientes e fornecedores. Essa extensão, que se dá pela integração externa, é o que se chama de gerenciamento da cadeia de abastecimento".

Há consenso na literatura sobre a necessidade de manter permanentemente a atenção com as atividades logísticas. O planejamento destas atividades deve ir além dos limites da empresa, integrando todos os membros de um mesmo canal na sua gestão, de forma a torná-lo mais competitivo.

Embora os conceitos de gerenciamento da cadeia de suprimentos antecedam os princípios propostos pelo ECR, foi a própria dinâmica de mercado que criou as condições práticas necessárias à divulgação mais ampla dos conceitos relativos à idéia de supply chain. O movimento ECR surge nos Estados Unidos, no fim da década de 80 , como resposta dos supermercados, que vinham perdendo espaço para a rede Wal Mart e para novos formatos de loja, tais como os clubes de desconto e os superstores ${ }^{(2)}$. 
O ECR propõe quatro diferentes estratégias: reposição, sortimento, promoção e introdução eficiente de produtos. Com a reposição eficiente, de acordo com o manual da Associação ECR Brasil (1998), busca-se otimizar o tempo e o custo do sistema de reposição. O sortimento eficiente visa a otimizar os estoques e espaços da loja. A introdução eficiente de novos produtos objetiva maximizar a eficácia do desenvolvimento e lançamento de novos produtos. Por último, por promoção eficiente entende-se maximizar os benefícios de todo o sistema de promoção de venda ao varejo e ao consumidor final.

A operacionalização do ECR requer o seguinte elenco.

. EDI. O eletronic data interchange (EDI) pode ser entendido como a troca de documentos comerciais e financeiros entre empresas, realizada por computadores, em um formato padrão. O EDI é, até hoje, uma prática que ocorre com o auxílio das value added networks, popularmente conhecidas como VANs (ou seja, redes de valor agregado). As VANs são empresas que oferecem ao mercado o serviço de troca eletrônica de dados.

. Reposição contínua. Trata-se da reposição próxima ao just in time, com base nas informações do ponto de venda.

. Cross docking. Reda (1999, p. 1) define o procedimento como sendo a atividade de mover "produtos do caminhão do fornecedor, através do centro de distribuição, para outro caminhão com destino às lojas, sem colocá-los nas áreas de armazenagem ou de preparação do pedido".

. Entrega direto nas lojas. Corresponde à entrega direta das mercadorias da fábrica nos pontos de venda. Aparentemente, há uma incoerência entre duas práticas consideradas importantes para o ECR, o cross docking e a entrega direto na loja. Essa incoerência reside no fato de que o cross docking acontece no centro de distribuição, cuja existência, a princípio, não condiz com a entrega das mercadorias diretamente nas lojas; entretanto deve-se ter em mente que a entrega direto na loja é interessante para apenas uma parcela do mix. Um estudo do Boston Consulting Group e da Milton Merl \& Associates, citado por Lewis (1998), revela importantes ganhos na utilização combinada de entrega direta e cross docking.

. Emissão de pedidos por computador, ou computer assisted ordering (CAO), com base nas informações coletadas pelos PDVs.

- Gerenciamento de categorias. Consiste na definição de categorias de produtos como unidades estratégicas de negócios, sempre considerando as necessidades do consumidor.

- Activity based costing (ABC). Para identificação, análise e alocação de custos. 
. Parcerias. Acordos objetivando maximizar os retornos da cadeia.

Da relação acima, tendo em vista o escopo deste estudo, cumpre excluir o $\mathrm{ABC}, \mathrm{o}$ gerenciamento de categorias e as parcerias, uma vez que os dois primeiros não são diretamente ligados à logística. Já as parcerias não devem ser consideradas como práticas ou técnicas e sim princípios.

\section{As Ferramentas para o ECR}

Durante a $4^{\mathrm{a}}$ Conferência sobre Efficient Consumer Response, do Food Marketing Institute, realizada em Atlanta, nos Estados Unidos, em março de 1998, foram consultados vários especialistas. Posteriormente foi feita uma revisão da literatura, que permitiu identificar os requisitos logísticos necessários para o ECR. Também foram consultados técnicos e executivos de empresas nacionais.

Para que as mercadorias possam ser repostas de forma contínua e automatizada, com emissão de pedido pelo computador e recepção eletrônica, é preciso que a informação da necessidade de reposição esteja disponível. Essa informação é obtida a partir dos dados da saída das mercadorias nos check outs das lojas e na sua entrada tanto nos centros de distribuição como nos depósitos das lojas. Dessa forma, deve-se trabalhar com check outs automatizados, bem como coletar a informação da entrada dos produtos no centro de distribuição e nos depósitos das lojas. Embora essa coleta de informações possa ser feita de forma manual, na operação em grandes volumes ela ocorreria de forma mais eficiente se fossem usados leitores óticos (scanners). Evidentemente, o uso de leitores óticos pressupõe que as mercadorias sejam identificadas por códigos de barras.

Para que o conhecimento dos níveis de estoque possa gerar pedidos de reposição é preciso que essa informação, vinda dos check outs e dos sistemas dos depósitos, esteja permanentemente atualizada no sistema de compras ou no sistema que faz os pedidos, com freqüência que não comprometa adequadas condições operacionais.

Para o gerenciamento do estoque pelo fornecedor, além dos check outs automatizados e da possibilidade de acompanhamento dos níveis de estoque e da identificação dos produtos por meio de códigos de barra, há a necessidade de uma parceria com os fornecedores envolvidos. Essa parceria deve avançar além do compartilhamento das informações necessárias ao monitoramento dos níveis de estoque pelo fornecedor, indo até o entrosamento das áreas de transporte e armazenagem de todos os envolvidos, de modo a fazer com que a reposição dos produtos ocorra da melhor forma possível. 
Embora a rigor a técnica do cross docking seja possível sem o apoio de sistemas de informática e automatização, a sua operação com grandes fluxos de mercadorias e de forma integrada às necessidades da empresa necessita desse suporte. Assim, os leitores óticos, o código de barras e a troca eletrônica de dados possibilitam a coordenação da operação, viabilizando a integração com as lojas, os fornecedores e as transportadoras. Tendo em vista a característica dinâmica dessa técnica, é interessante que os tempos de carga e descarga no depósito não sejam elevados a ponto de comprometê-la.

A entrega diretamente na loja é um caso semelhante ao cross docking. A técnica em si não exige aparato tecnológico sofisticado, mas a sua utilização em volumes grandes, e integrada a sistemas que permitam o gerenciamento de categoria, sim. Passa-se, então, a necessitar de check outs automatizados, integrados ao sistema de compra ou corporativo, da troca eletrônica de dados, bem como dos recursos necessários à automatização do recebimento já mencionados. De forma esquemática, a decomposição realizada a partir das quatro estratégias do ECR até os requisitos logísticos está resumida e representada na Figura 1.

\section{Figura 1: O ECR, suas Estratégias, Práticas, Técnicas e Ferramentas}

\begin{tabular}{|c|c|c|}
\hline Requisitos & Práticas e técnicas & \\
\hline \multirow[b]{2}{*}{$\begin{array}{l}\text { - Check outs } \\
\text { automatizados } \\
\text { - Leitores } \\
\text { óticos } \\
\text { - Código de } \\
\text { barras } \\
\text { - Nível de } \\
\text { serviço } \\
\text { adequado na } \\
\text { carga e } \\
\text { descarga }\end{array}$} & \multirow[b]{2}{*}{$\begin{array}{l}\text { - Reposição contínua } \\
\text { - Pedidos feitos pelo } \\
\text { computador } \\
\text { - Estoque gerenciado } \\
\text { pelo fornecedor } \\
\text { - Recepção } \\
\text { eletrônica } \\
\text { - Cross docking } \\
\text { - Entrega direto na } \\
\text { loja } \\
\text { - EDI }\end{array}$} & Es tratégias \\
\hline & & $\begin{array}{l}\text { - Reposição } \\
\text { eficiente } \\
\text { - Sortimento } \\
\text { eficiente } \\
\text { - Promoção } \\
\text { eficiente } \\
\text { - Introdução } \\
\text { eficiente de } \\
\text { novos } \\
\text { produtos }\end{array}$ \\
\hline
\end{tabular}

Da discussão anterior pode-se perceber, primeiramente, a importância da troca eletrônica de dados, troca esta que participa, ainda que indiretamente, de todas as demais práticas e técnicas. Em seguida, merece menção o check out automatizado, que alimenta o sistema com a necessidade de reposição. A entrada de mercadorias na empresa, com o seu reflexo nos sistemas de informação, é grande- 
mente facilitada pela recepção eletrônica, com o uso de leitores óticos dos códigos de barras. Uma vez de posse dos itens acima, os demais passam a ser viáveis.

\section{A Situação dos Supermercados Brasileiros na Área de Logística}

Na seção anterior identificaram-se os seguintes requisitos logísticos para a adoção do ECR: troca eletrônica de dados, check outs automatizados, código de barras, leitores óticos e recepção eletrônica das mercadorias, cross docking, gerenciamento do estoque pelo fornecedor, emissão de pedidos de compra pelo computador, reposição contínua, nível de serviço adequado na carga e descarga dos caminhões e entrega direto na loja. Estes elementos foram então avaliados, considerando uma amostra de empresas supermercadistas. A seguir descrevem-se os procedimentos utilizados para o levantamento da amostra e analisam-se os resultados.

\section{O Método, a População e a Amostra}

Realizada a revisão da literatura com o objetivo de identificar os requisitos na área de logística para a adoção da estratégia do efficient consumer response e acrescidas essas informações com dados colhidos junto a especialistas, estruturou-se uma pesquisa entre as empresas supermercadistas com a finalidade de levantar o estágio atual de domínio dos mencionados requisitos.

Para a coleta de dados utilizou-se um questionário enviado por fax e por correio eletrônico aos supermercados, juntamente com uma carta explicativa a respeito do estudo, na qual se solicitava o autopreenchimento. Os questionários foram devolvidos também por fax e por correio eletrônico.

Levando-se em conta que o ECR é uma estratégia com certa sofisticação, decidiu-se limitar a investigação às maiores empresas de supermercados do Brasil. Dessa forma, a população de interesse constituiu-se das grandes empresas da área de supermercados que operam no país.

Devido às dificuldades de custo e operacionais para realizar um estudo de caráter censitário, optou-se por um levantamento baseado em amostra. Essa amostra contou com 21 empresas, que em conjunto representavam, em 1998, pouco menos que $25 \%$ do faturamento do setor supermercadista. Os supermercados componentes da amostra eram responsáveis também por $12 \%$ do emprego e detinham, em conjunto, $1,3 \%$ do total de lojas (Araújo, 1999). 
Considerando-se esses dados, e tendo em conta que as 8 maiores redes são responsáveis por $57 \%$ das vendas do setor supermercadista (ABRAS, 1999), pode-se assumir que a amostra representa uma parcela razoável da população em estudo.

$\mathrm{Na}$ seqüência apresentam-se os resultados da pesquisa de campo conduzida nas redes varejistas.

\section{Resultados}

Os resultados são apresentados considerando cada um dos requisitos anteriormente identificados para a implantação da estratégia ECR.

\section{A Troca Eletrônica de Dados - EDI}

As empresas da amostra trabalham com grande número de fornecedores. A média de fornecedores ativos por empresa é de 2.123 , sendo o valor máximo informado de 6.800. As mercadorias desses fornecedores, na maioria dos casos (76\%), passam por um centro de distribuição antes de atingir as lojas.

O sistema de compras das empresas que responderam ao questionário possui um grau de integração elevado com os outros sistemas da área logística, como se pode verificar na Figura 2, a seguir, que mostra a porcentagem de casos em que essa integração existe.

Apesar da existência de integração dos sistemas internos, verificou-se que o EDI ainda não é amplamente difundido entre as empresas da amostra. Em média, a troca eletrônica de dados existe no processo de compra das empresas há apenas 1 ano e 3 meses. Das 21 empresas pesquisadas, 14 afirmaram que não fazem troca eletrônica de dados com nenhum parceiro comercial e 7 disseram que praticam o $\mathrm{EDI}^{(3)}$ com um ou mais parceiros. Assim sendo, pode-se dividir a amostra em dois grupos, um composto pelas empresas que usam EDI e outro com as empresas que não o usam. As características desses grupos são, sinteticamente, as seguintes.

. Grupo 1 - empresas que praticam EDI: usam EDI há 1 ano ou mais; todas usam EDI com fornecedores (de 5 a 309 fornecedores), possuem de 215 a 6.800 fornecedores ativos, têm de 9 a 285 lojas e faturam de R $\$ 665.066 .300$ a $\mathrm{R} \$ 5.470 .301 .723$ por ano. 
. Grupo 2 - empresas que não praticam EDI: possuem de 750 a 3.500 fornecedores ativos, têm de 4 a 26 lojas e faturam de $\mathrm{R} \$ 33.768 .549$ a $\mathrm{R} \$ 898.878 .393$.

\section{Figura 2: Integração do Sistema de Compra}

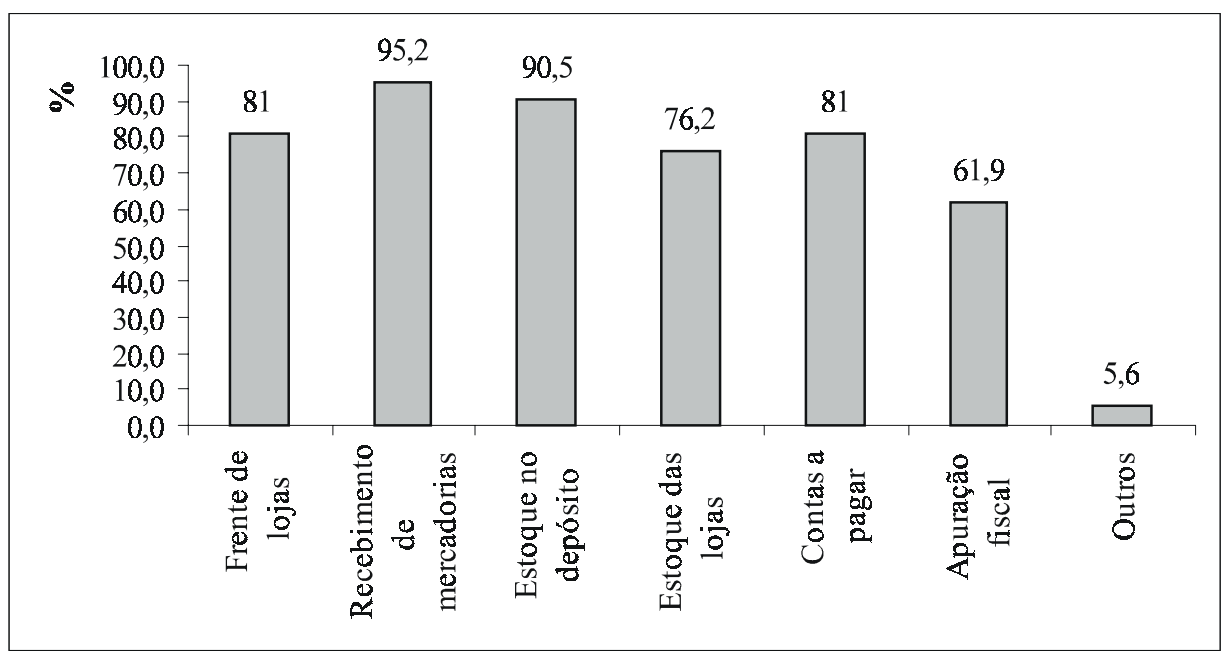

Entre os documentos mais transmitidos por EDI encontram-se os pedidos de compra, enviados por $38,1 \%$ da amostra, e as informações sobre o nível do estoque, por $14,3 \%$. Apenas $9,5 \%$ das empresas pesquisadas informaram que usam o EDI para transmitir notas fiscais, vendas e promoções. Nenhuma empresa usa o EDI para informar a previsão de vendas.

A baixa integração entre os sistemas da área de logística entre as empresas também se reflete nos cronogramas de abastecimento, que são utilizados por apenas $29 \%$ dos integrantes da amostra. A grande maioria continua a fazer uso de pedidos pontuais, preenchidos quando os estoques atingem um nível mínimo preestabelecido.

\section{Check Outs Automatizados}

A grande maioria das empresas pesquisadas já possui check outs automatizados. Em $85,7 \%$ das empresas da amostra, $100 \%$ das lojas possuem check outs automatizados. Praticamente todas as empresas têm seus check outs com leitores de códigos de barra. Isso acontece em 19 empresas, ou seja, 90,5\% da amostra. Além disso, $65 \%$ das empresas também estão preparadas para operar com transferência eletrônica de fundos. Deve-se notar que $81 \%$ das empresas da amostra informaram que seus check outs estão integrados com o sistema de compras da 
empresa. Esse aspecto é um requisito importante para que o supermercado possa emitir pedidos de compra aos fornecedores por meio de computador.

Quando indagados se os dados colhidos nos check outs são utilizados como um banco de dados, a fim de se conhecer os hábitos de compra dos clientes, apenas $25 \%$ das empresas disseram que sim, $40 \%$ disseram que isso ocorre de forma parcial, e 35\% disseram que esses dados não são utilizados. Vale lembrar que os dados dos check outs podem ser úteis para diversas finalidades, como o acompanhamento e previsão da demanda, para as decisões relativas à determinação de níveis ideais de estoque, e mesmo para o planejamento de promoções.

\section{Código de Barras}

Para que o fluxo de informações ligadas à área logística ocorra de forma correta é preciso que haja uma identificação padronizada dos produtos aos quais essas informações se referem e também que cada item (stock keeping unit - SKU ou unidade mantida em estoque) esteja identificado. Além disso, para a operação com grandes volumes é necessário que a identificação seja feita rapidamente e com confiabilidade. Dessa forma, o código de barras, capaz de ser lido por leitores óticos (scanners), é de grande importância, pois permite a captação de informações que podem ser introduzidas diretamente nos sistemas da empresa.

Embora haja um trabalho que busca a padronização dos códigos de barras (EAN), muitas empresas ainda usam códigos de identificação próprios. Neste estudo não foi investigado se os códigos de barras, eventualmente utilizados, correspondem ao padrão da EAN.

Segundo as empresas integrantes da amostra, o controle das atividades por meio de códigos de barras nas áreas de armazenagem ocorre em 42,9\% dos casos na recepção das mercadorias, em 19,0\% na área de movimentação, em $14,3 \%$ na área de picking (a área de preparação do pedido) e em 23,8\% na expedição de mercadorias. Nos inventários do estoque o código de barras é utilizado em $47,6 \%$ dos casos. Na frente de lojas, as 20 empresas que responderam a essa questão se encontram em muito melhor situação: 95\% afirmaram que possuem check outs com leitores de códigos de barras.

\section{Leitores Óticos e Recepção Eletrônica das Mercadorias}

Apenas 23,8\% das empresas pesquisadas afirmaram possuir leitores óticos no depósito central; somente $14,3 \%$ usam radiofreqüência para transmitir informações para o sistema. Como 42,9\% das empresas disseram efetuar o controle 
da recepção de mercadorias com códigos de barras, presume-se que neste caso estejam referindo-se à recepção nas lojas; caso contrário, haveria uma incoerência com a resposta anterior. Como já foi visto, $95 \%$ dos check outs estão equipados com leitores óticos; portanto esse aspecto não apresenta dificuldade para a adoção do ECR.

A recepção eletrônica das mercadorias, segundo os dados mencionados, encontra-se mais avançada nas lojas do que nos depósitos centrais, embora mesmo nas lojas essa ainda não seja a situação mais freqüente.

\section{Cross Docking}

Antes de considerar especificamente a questão do cross docking, importa tecer algumas considerações sobre as condições de armazenagem nas empresas varejistas componentes da amostra. Nos armazéns, o critério mais empregado para a definição do layout interno é o da divisão por categoria de produtos. Na estrutura dos armazéns existem áreas específicas para algumas atividades.

Os armazéns das empresas pesquisadas já recebem algum tipo de automação (em $62 \%$ dos casos), embora de forma parcial. Em $29 \%$ dos casos existem sistemas de endereçamento automático na entrada das mercadorias, havendo igual porcentagem no endereçamento na saída. O sistema do depósito está integrado ao sistema corporativo em $43 \%$ das empresas da amostra.

Verifica-se que na maioria dos casos a capacidade dos sistemas de armazenagem não está esgotada. Mantidas as instalações e condições atuais, todas as empresas da amostra revelaram ser possível ampliar o fluxo de mercadorias no estoque. Um aumento da quantidade de mercadorias em estoque só seria impossível para $10 \%$ das organizações pesquisadas.

Os paletes, estrados de madeira, ou outro material, sobre os quais a carga é disposta de modo a facilitar sua movimentação, já são bastante empregados. Segundo a pesquisa de campo, $75 \%$ das empresas usam o sistema de paletes, empregando-o, em média, em $62 \%$ das mercadorias.

A distribuição física com uso de frota própria continua a ser muito usada, pois $76 \%$ das empresas da amostra afirmaram não haver terceirizado essa atividade. Por outro lado, $81 \%$ das empresas não fazem o monitoramento à distância desses veículos. Apenas dois terços da amostra responderam qual o percentual de mercadorias entregues na hora e data programada, mas para essas empresas o desempenho do sistema de transporte com relação à pontualidade foi razoável, considerando os valores apresentados em outros segmentos do varejo brasileiro. Em média, 69\% das mercadorias são entregues na hora e data programadas. 
Relativamente ao cross docking, segundo as empresas o percentual de fornecedores que participam dessa atividade é de $24 \%$, em média; entretanto deve-se ressaltar que essa média se refere apenas a 7 empresas, já que as demais não fazem cross docking. Mesmo entre as empresas que fazem cross docking, a distribuição das respostas deve ser vista com certo cuidado, pois a variabilidade é muito grande: o menor valor registrado foi $5 \%$ e o maior $60 \%$.

\section{Gerenciamento do Estoque pelo Fornecedor}

Não foi perguntado de forma direta se a empresa deixava o gerenciamento de estoque, ou parte dele, a cargo do fornecedor. Essa decisão deveu-se ao fato de esse procedimento, no dia-a-dia, receber diferentes denominações, o que poderia acarretar mal-entendidos e comprometer as respostas. Em vez disso, optou-se por verificar se a empresa dispunha dos recursos necessários para essa prática. Assim, na seção compra de mercadorias do questionário verificou-se que apenas $14,3 \%$ das empresas compartilham a informação do nível de estoque por EDI. As respostas relativas a compartilhamento de informações sobre promoções e vendas obtiveram valores ainda menores $(9,5 \%)$.

\section{Emissão do Pedido de Compras pelo Computador}

De forma análoga ao que foi feito no gerenciamento do estoque pelo fornecedor, no item emissão do pedido de compras pelo computador buscou-se verificar os recursos necessários para que este fosse viável.

Foi feito um cruzamento estatístico entre as respostas positivas das perguntas referentes à integração do sistema de compras da empresa com os check outs (automatizados) e com o estoque do depósito, com o estoque das lojas e com a transmissão de pedidos de compra via EDI. Supõe-se que, de posse desses requisitos, as empresas estejam aptas a emitir seus pedidos de compra pelo computador. Das empresas integrantes da amostra, apenas 33,3\% se enquadraram nessa condição. As empresas que foram reunidas nesse agrupamento possuem características muito distintas, com diferenças enormes de faturamento. $\mathrm{O}$ aspecto que parece comum a essas empresas é realmente o relativo à política de investir na área de informações.

\section{Reposição Contínua}

Das 21 empresas que integram a amostra, 13 informaram que não fazem reposição contínua. Entre as 8 que adotam essa prática, o percentual médio de produtos envolvidos é $61 \%$. 


\section{Nível de Serviço Adequado na Carga e Descarga dos Caminhões}

Para uma operação com grandes quantidades de mercadorias e cujo aumento se pretende, é preciso que haja compatibilidade entre a capacidade dos depósitos, estoques e docas, para que nesses pontos não seja criado um funil, que venha a prejudicar o sistema como um todo. Nas empresas da amostra, o tempo médio de carga e descarga dos caminhões, incluindo a fila de espera, é de uma hora e meia, havendo pouca dispersão nas respostas. Esse desempenho nas operações de carga e descarga talvez possa ser explicado pelo fato de a paletização das cargas estar muito difundida. Embora esse nível de serviço seja considerado razoavelmente bom, com certeza pode ser melhorado, se aferido pelos padrões internacionais.

\section{Entrega Direto na Loja}

Na pesquisa de campo verificou-se que $23,8 \%$ das empresas não possuem centro de distribuição. Também se constatou que, em média, $34,8 \%$ das compras realizadas pelas empresas pesquisadas são feitas de forma descentralizada, ou seja, são efetuadas independentemente pelas lojas. Para as empresas que possuem centro de distribuição, o percentual médio de respostas acerca das mercadorias de seu mix que são entregues nesse depósito central foi de $55,4 \%$, pelo que se conclui que $44,6 \%$ das mercadorias são entregues diretamente nas lojas.

\section{CONCLUSÖES}

O número de fornecedores com os quais um supermercado se relaciona é grande. Esse aspecto, associado à própria dinâmica da atividade, exige atualmente automação dos processos gerenciais. O levantamento realizado revelou que, se por um lado os sistemas de informação já possuem grau razoável de integração dentro dos limites da empresa, o mesmo não se verifica nas cadeias de abastecimento. Mesmo dentro das empresas, essa automação não é distribuída de forma uniforme, porquanto se verificou uma preocupação acentuadamente maior com as condições operacionais existentes na frente de loja. Provavelmente os investimentos na automação, em especial dos check outs, são explicados pela necessidade de adaptação das empresas à legislação, o que exigiu a emissão de cupons fiscais. Como não há essa pressão na retaguarda das lojas, é possível que a automação e a integração desses sistemas demorem um pouco mais.

A principal causa da falta de integração das informações entre os membros da 
cadeia de abastecimento é a baixa utilização da troca eletrônica de dados, o EDI. Apenas 33\% da amostra pesquisada usa essa tecnologia. Embora este aspecto não tenha sido objeto deste estudo, pode-se especular as possíveis razões para a não utilização do EDI. Entre as várias causas possíveis, uma das mais importantes é provavelmente o seu custo. Como atualmente há a possibilidade de migração de uma boa parte do fluxo de informações das VANs para a Internet, é possível que em breve essa deficiência das empresas venha a ser reduzida. Também é interessante observar que, nos casos em que é utilizado, o EDI é praticado há relativamente pouco tempo.

$\mathrm{O}$ requisito que apresenta o menor grau de dificuldade para o ECR é, sem dúvida, a existência nas empresas de check outs automatizados, integrados ao sistema corporativo. Outro requisito em que a situação não apresenta maiores problemas é no nível de serviço da carga e descarga dos caminhões. Os tempos, embora possam ser melhorados, são considerados pelos especialistas da área, se comparados com outros segmentos do varejo brasileiro, razoavelmente bons.

Técnicas que envolvem operações um pouco mais sofisticadas, como a reposição contínua, a entrega direto na loja e o cross docking, não são largamente empregadas. Apenas $38 \%$ das empresas praticam a reposição contínua; a entrega direto na loja ocorre parcialmente entre as empresas que possuem centro de distribuição; o cross docking só é realizado por um terço da amostra.

$\mathrm{O}$ fato de haver falta de leitores óticos na área de retaguarda, principalmente nos depósitos centrais, dificulta a recepção eletrônica que, dessa forma, é mais empregada nas lojas. A deficiência em relação ao EDI e aos leitores óticos de código de barras prejudica a emissão de pedidos pelo computador, de modo que apenas um terço das empresas pesquisadas estão em condições de utilizar essa prática. A deficiência no EDI também prejudica o gerenciamento do estoque pelo fornecedor.

Em síntese, pode-se concluir que as maiores deficiências se encontram nas áreas de informação, mais especificamente em dois aspectos: troca eletrônica de dados, de modo a permitir a troca de informações diretamente entre os seus computadores e os de seus fornecedores; e na falta de leitores óticos de código de barras, para serem usados nas áreas de retaguarda. Considerando-se as definições mais recentes de logística, que enfatizam a visão de gerenciamento da cadeia de abastecimento, percebe-se claramente que essa falta de integração dos sistemas de informação, ao longo da cadeia, compromete a adoção do ECR.

Ademais, pode-se notar que, nas atividades mais tradicionalmente associadas à logística, ao transporte e à armazenagem, a situação é mais favorável, com 
desempenhos razoáveis, em termos de tempo para carga e descarga e existência até mesmo de certa folga na capacidade de estoque. Esse fato pode ser considerado um elemento favorável à adoção do ECR.

Pesando-se todos esses aspectos, pode-se concluir que embora as atividades mais básicas não pareçam empecilhos para a adoção do ECR pelos supermercados brasileiros, o mesmo não acontece com o fluxo de informações: caso não sejam feitos os investimentos necessários, haverá grandes dificuldades à implementação dessa proposta de estratégia.

Este estudo limitou-se a estudar as exigências impostas pela logística à introdução do ECR. É evidente que a adoção e disseminação de tais princípios transcendem qualquer área específica. O ECR requer, fundamentalmente, forte mudança cultural, sendo este um aspecto que pode ser apontado como possível extensão do presente trabalho.

\section{NOTAS}

${ }^{1}$ A AC Nielsen considera cadeias a situação em que há cinco ou mais lojas com o mesmo nome.

${ }^{2}$ Segundo Dib (1997), os superstores, além de oferecer amplo sortimento, colocam à disposição do consumidor vasta gama de serviços, como agência de turismo, bancos etc.

${ }^{3}$ Deve-se ressaltar que há coerência nas respostas. As empresas que disseram não utilizar o EDI informaram que não trocam nenhum documento por via eletrônica e deixaram em branco a pergunta há quantos anos sua empresa pratica EDI.

\section{ReFERÊNCIAS BibLIOGRÁFICAS}

\section{AC NIELSEN.}

Estrutura do varejo brasileiro. Censo, 1999.

\section{ANTENA DIGITAL.}

Info Exame, outubro 1999. p. 22-25.
ARAÚJO, J. H. P.

Ranking da Abras mostra a evolução dos supermercados. Superhiper, maio 1999. p. 03.

ASSOCIAÇÃO ECR BRASIL.

ECR Brasil - visão geral / potencial de redução de custos e otimização de processos. São Paulo, 1998. 
BALLOU, R. H.

Logística empresarial. São Paulo : Atlas, 1995.

BERMAN, B.;

EVANS, J. R.

Retail management : a strategic approach. 4. ed. London : MacMillan, 1989.

BOWERSOX, D. J.;

CLOSS, D. J.

Logistical management : the integrated supply chain process. New York : McGraw-Hill, 1996.

DIB, J. A.

Efficient consumer response (ECR) : uma estratégia para o varejo de bens de consumo de massa. Revista de Administração, p. 14-22, abr./jun. 1997.
GAZETA MERCANTIL.

São Paulo, 01 out. 1996.

IANNI, O.

Teorias da globalização. Rio de Janeiro : Civilização Brasileira, 1995.

LEWIS, L.

DSD : unleashing the power. Progressive Grocer, p. 04-06, Nov. 1998.

PORTER, M.

Vantagem competitiva. Rio de Janeiro : Campus, 1989.

REDA, S.

Crossdocking : can supermarkets catch up? Stores, p. 01-06, July 1999.

WATERS, M.

Globalization. London : Routledge, 1996. 